\title{
Effects of Surya Nadi Pranayama on Components of Health-Related Fitness
}

\author{
Baljinder Singh Bal \\ Department of Physical Education (T), Guru Nanak Dev University, Amritsar, India
}

Email address:

bal_baljindersingh@yahoo.co.in

To cite this article:

Baljinder Singh Bal. Effects of Surya Nadi Pranayama on Components of Health-Related Fitness. American Journal of Health Research. Vol. 3, No. 1, 2015, pp. 46-51. doi: 10.11648/j.ajhr.20150301.17

\begin{abstract}
The present study was conducted with the objective to determine the short term practice of Surya Nadi pranayama on components of health-related fitness. For the purpose of present study 36 university level girls between the age group of 2126 years were selected. The subjects were purposively assigned into two groups: Group-A: Experimental $\left(\mathrm{n}_{1}=18\right)$; Group-B: Control $\left(\mathrm{n}_{2}=18\right)$. The subjects from Group-A: Experimental were subjected to a 4-weeks Surya Nadi pranayama. Student $\mathrm{t}$ test for paired samples was utilized to compare the means of the pre-test and the post-test. Based on the analysis of the results obtained, we conclude that the significant differences were found in components of health-related fitness (i.e., cardiorespiratory endurance, flexibility) of university level girls. There was no significant difference between two groups were noted in muscular strength, muscular endurance, \% body fat, fat weight and lean body weight of university level girls.
\end{abstract}

Keywords: Surya Nadi Pranayama, Components of Health-Related Fitness

\section{Introduction}

The ancient research in relation to attaining purification of human body, mind, and soul is commonly brought under the umbrella term of "Pranayama". Speaking etymologically, "Pranayama" is a Sanskrit word comes from the roots prana (universal energy), and yama (to control). As a deep breathing technique, pranayama reduces dead space ventilation and decreases work of breathing. It also refreshes air throughout the lungs, in contrast with shallow breathing that refreshes air only at the base of the lungs (Bijilani, 2004). Breath is a dynamic bridge between the body and mind (Bjlani, 2004). Breathing is not only an instinctive reflex to satisfy the need of the body for oxygen but it has been considered that consciously controlled breathing can be used as a technique for enhancing mental and physical powers (Gharote, 2003). Pranayama produce different physiological responses in healthy young volunteers (Madanmohan et al, 2005, Shivraj et al, 2001). Pranayama is a method of breathing and chest expansion exercise which has been reported to improve cardio respiratory function in health and disease. The practice of pranayama has been known to modulate cardiac autonomic status with an improvement in cardio respiratory functions (Subalakshmi et al, 2005). The practice of breathing exercise increases parasympathetic activity and decreases sympathetic activity, improves cardiorespiratory functions by affecting oxygen consumption, metabolism and skin resistance (Pal et al, 2004, Ropa et al, 2001). Delimiting the scope of present discussion Surya nadi pranayama is one of the main pranayamas. That refers to the breathing exercise in which you inhale through the right nostril and exhale through the left. There have been numerous studies on pranayama and its effects on physical function. However, on account of phenomenal and ever increasing popularity of breathing techniques in the past few years, there is a surprising lack of research in this specific area. This precise reason has prompted us to undertake this study with the aim to find out the effects of surya nadi pranayama on components of health-related fitness.

\section{Material and Methods}

\subsection{Subjects}

Thirty six, university level girls between the age group of 19-25 years were selected. The subjects were purposively assigned into two groups: Group-A: Experimental $\left(\mathrm{n}_{1}=18\right)$; Group-B: Control $\left(\mathrm{n}_{2}=18\right)$. 
Table 1. Distribution and Demographics of Subjects

\begin{tabular}{llll}
\hline \multicolumn{2}{l}{ Sample Size $(\mathbf{N}=\mathbf{3 6})$} & & \\
\hline Variables & Total $(\mathbf{N}=\mathbf{3 6})$ & $\begin{array}{l}\text { Experimental group } \\
\left(\mathbf{n}_{\mathbf{1}}=\mathbf{1 8}\right)\end{array}$ & $\begin{array}{l}\text { Control group } \\
\left(\mathbf{n}_{\mathbf{2}}=\mathbf{1 8}\right)\end{array}$ \\
\hline Age & $22.027 \pm 1.963$ & $22 \pm 1.940$ & $22.055 \pm 2.042$ \\
Body Height & $5.322 \pm 1.396$ & $5.311 \pm 1.450$ & $5.333 \pm 1.371$ \\
Body Mass & $56 \pm 2.484$ & $55.666 \pm 2.589$ & $56.333 \pm 2.400$ \\
\hline
\end{tabular}

\subsection{Methodology}

This study is designed as a retrospective cross-sectional study. The subjects from Group-A: Experimental were subjected to a 4-weeks training of Kapalbhati Pranayama. This lasted 4 weeks and consisted of daily sessions. The cooper 12 minute run test was used to measure cardiorespiratory endurance. Muscular strength was measured by sit up test. Push up test was used to measure muscular endurance, Flexibility was measured by sit and reach test and Hydrostatic weighing technique was used for the measurement of fat and lean body tissue in a clinical setting.

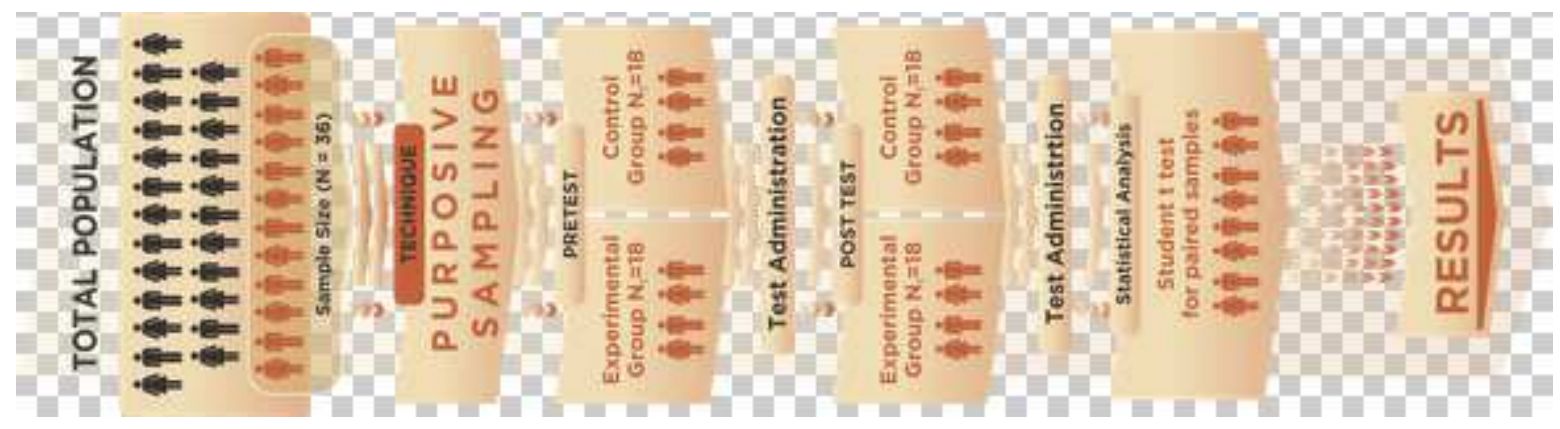

Figure 1. Study Design

Table 2. Experimental Treatment

\begin{tabular}{|c|c|c|c|}
\hline \multicolumn{4}{|c|}{ 4-Weeks Surya Nadi Pranayama Training } \\
\hline Weeks & Schedule & Time & Duration \\
\hline \multirow{3}{*}{$\mathrm{I}^{\mathrm{st}}$ Week } & Preliminary Yogic Exercises & 5 Minute & \multirow{3}{*}{20 Minute } \\
\hline & Practice of Surya Nadi Pranayama (9 Rounds X 1 Set) & 10 Minute & \\
\hline & Relaxation Posture & 5 Minute & \\
\hline \multirow{3}{*}{$2^{\text {nd }}$ Week } & Preliminary Yogic Exercises & 5 Minute & \multirow{3}{*}{25 Minute } \\
\hline & Practice of Surya Nadi Pranayama (9 Rounds X 2 Set) & 15 Minute & \\
\hline & Relaxation Posture & 5 Minute & \\
\hline \multirow[t]{2}{*}{$3^{\text {rd }}$ Week } & Practice of Surya Nadi Pranayama (9 Rounds X 3 Set) & 20 Minute & \multirow[t]{2}{*}{30 Minute } \\
\hline & Relaxation Posture & 5 Minute & \\
\hline \multirow{3}{*}{$4^{\text {rd }}$ Week } & Preliminary Yogic Exercises & 5 Minute & \multirow{3}{*}{35 Minute } \\
\hline & Practice of Surya Nadi Pranayama (9 Rounds X 4 Set) & 25 Minute & \\
\hline & Relaxation Posture & 5 Minute & \\
\hline
\end{tabular}

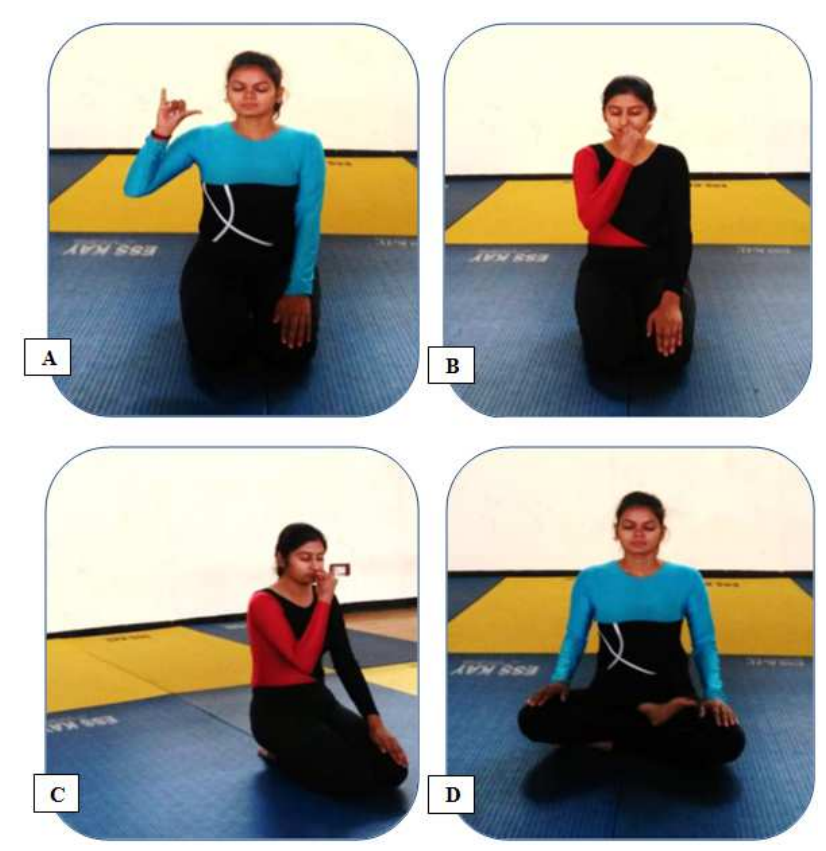

Figure 2. Subject Performing Surya Nadi Pranayama 
Table 3. Mean values $( \pm S D)$ and Paired Sample t-test of Components of Health-Related Fitness (i.e., Cardiorespiratory Endurance, Muscular Strength, Muscular Endurance, Flexibility, \% Body Fat, Fat Weight and Lean Body Weight) in Experimental and Control group ( $n=18$ each) before (Pre) and after (Post) 4-weeks Surya Nadi Pranayama Training Programme (Experimental group only).

\begin{tabular}{|c|c|c|c|c|c|}
\hline Parameters & Group & Pre-Test & Post-Test & t-value & p-value \\
\hline \multirow{2}{*}{ Cardiorespiratory Endurance } & Experimental & $1880.28 \pm 438.26$ & $1888.61 \pm 437.58$ & $9.964 *$ & 0.0001 \\
\hline & Control & $1952.78 \pm 406.83$ & $1953.94 \pm 408.41$ & 1.069 & 0.3000 \\
\hline Muscular Strength & Experimental & $35.89 \pm 6.64$ & $35.44 \pm 6.56$ & 1.409 & 0.1769 \\
\hline \multirow{2}{*}{ Muscular Endurance } & Experimental & $29.22 \pm 4.22$ & $29.61 \pm 4.20$ & 1.510 & 0.1492 \\
\hline & Control & $28.67 \pm 4.07$ & $28.83 \pm 3.63$ & 0.717 & 0.4827 \\
\hline Flexibility & Experimental & $26.56 \pm 5.23$ & $27.78 \pm 5.13$ & $5.500 *$ & 0.0001 \\
\hline \multirow{2}{*}{$\%$ Body Fat } & Experimental & $29.27 \pm 6.21$ & $29.26 \pm 6.20$ & 1.492 & 0.1539 \\
\hline & Control & $25.10 \pm 7.95$ & $25.10 \pm 7.94$ & 0.046 & 0.9639 \\
\hline \multirow{2}{*}{ Fat Weight } & Experimental & $16.57 \pm 1.49$ & $16.56 \pm 1.48$ & 1.229 & 0.2355 \\
\hline & Control & $16.41 \pm 1.27$ & $16.41 \pm 1.277$ & 0.000 & 1.0000 \\
\hline \multirow{2}{*}{ Lean Body Weight } & Experimental & $49.62 \pm 5.14$ & $49.65 \pm 5.15$ & 1.661 & 0.1149 \\
\hline & Control & $48.807 \pm 6.29$ & $48.808 \pm 6.291$ & 1.000 & 0.3313 \\
\hline
\end{tabular}

\section{Statistical Analyses}

Data is expressed as the mean $\pm \mathrm{SD}$. Student $\mathrm{t}$ test for paired samples was utilized to compare the means of the pretest and the post-test.

\section{Results}

\subsection{Cardiorespiratory Endurance}

The results of components of health-related Fitness in group (Experimental) and group (Control) are shown in Table 3. The Mean and Standard Deviation $( \pm \mathrm{SD})$ values of cardiorespiratory endurance of pre-test and post-test of experimental group were $1880.28 \pm 438.26 \& 1888.61 \pm 437.58$ respectively. However, the Mean and Standard Deviation $( \pm \mathrm{SD})$ values of cardiorespiratory endurance of pre-test and post-test of control group were 1952.78 \pm 406.83 \& $1953.94 \pm 408.41$. The t-value in case of experimental group was 9.964* and for control group it was 1.069 .
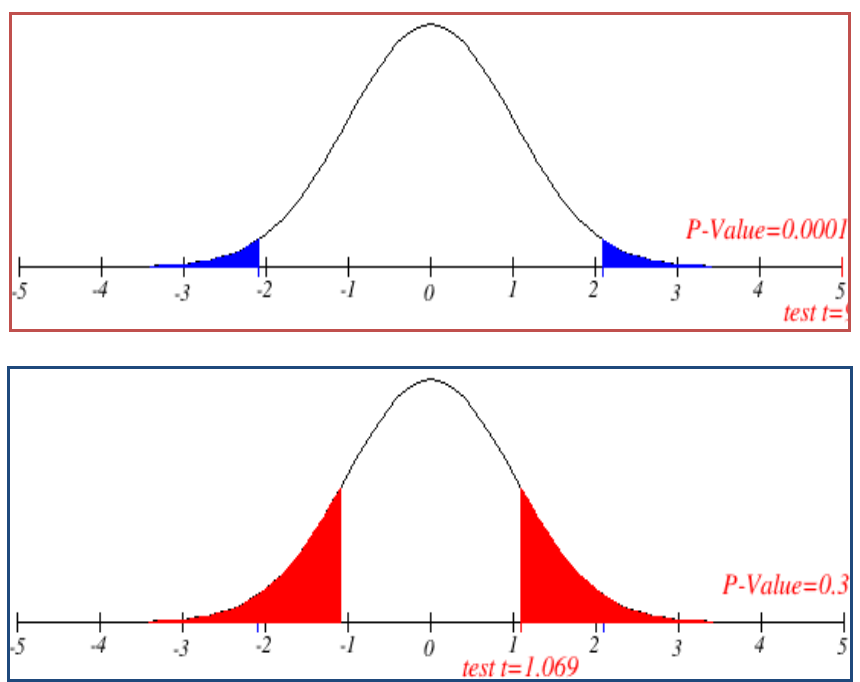

Figure 3. $t$-test and p-value for the Experimental (Pre-Test \& Post-Test) and Control (Pre-Test \& Post-Test) Groups of Health-Related Fitness (i.e., Cardiorespiratory Endurance) of University Level Girls.
Significant between-group differences were noted in cardiorespiratory endurance in the experimental group before (Pre) and after (Post) subjected to 4-weeks surya nadi pranayama training programme since, the calculated value of $\left(t=9.964^{*}\right)$ is greater than tabulated value of $t .05(17)=2.10$ for the selected degree of freedom and level of significance. However, no significant changes over that 4- weeks period were noted in the control group.

\subsection{Muscular Strength}

The results of components of health-related fitness in group (Experimental) and group (Control) are shown in Table 3 . The Mean and Standard Deviation $( \pm \mathrm{SD})$ values of muscular strength of pre-test and post-test of experimental group were $35.89 \pm 6.64 \& 35.44 \pm 6.56$ respectively. However, the Mean and Standard Deviation $( \pm \mathrm{SD})$ values of muscular strength of pre-test and post-test of control group were $35.17 \pm 6.49$ \& $34.94 \pm 6.40$. The t-value in case of experimental group was 1.409 and for control group it was 0.696 .
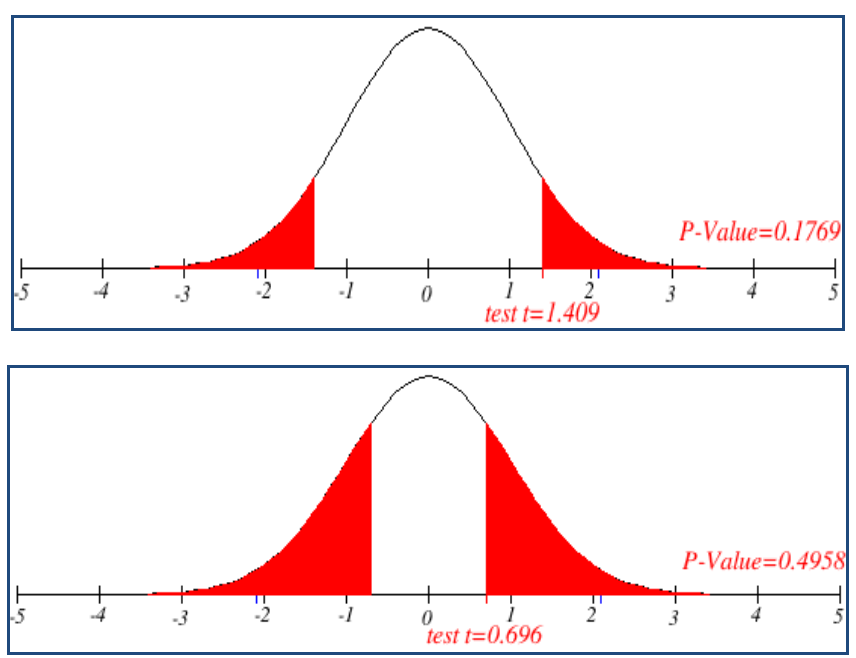

Figure 4. $t$-test and p-value for the Experimental (Pre-Test \& Post-Test) and Control (Pre-Test \& Post-Test) Groups of Health-Related Fitness (i.e., Muscular Strength) of University Level Girls. 
Insignificant between-group differences were noted in muscular strength in the experimental group before (Pre) and after (Post) subjected to 4-weeks surya nadi pranayama training programme since, the calculated value of $(\mathrm{t}=1.409)$ is greater than tabulated value of $t .05(17)=2.10$ for the selected degree of freedom and level of significance. However, no significant changes over that 4- weeks period were noted in the control group.

\subsection{Muscular Endurance}

The results of components of health-related fitness in group (Experimental) and group (Control) are shown in Table 3. The Mean and Standard Deviation $( \pm \mathrm{SD})$ values of muscular endurance of pre-test and post-test of experimental group were $29.22 \pm 4.22 \& 29.61 \pm 4.20$ respectively. However, the Mean and Standard Deviation $( \pm \mathrm{SD})$ values of muscular endurance of pre-test and post-test of control group were $28.67 \pm 4.07 \& 28.83 \pm 3.63$. The $t$-value in case of experimental group was 1.510 and for control group it was 0.717 .

Insignificant between-group differences were noted in muscular endurance in the experimental group before (Pre) and after (Post) subjected to 4-weeks surya nadi pranayama training programme since, the calculated value of $(\mathrm{t}=1.510)$ is greater than tabulated value of $t .05(17)=2.10$ for the selected degree of freedom and level of significance. However, no significant changes over that 4- weeks period were noted in the control group.
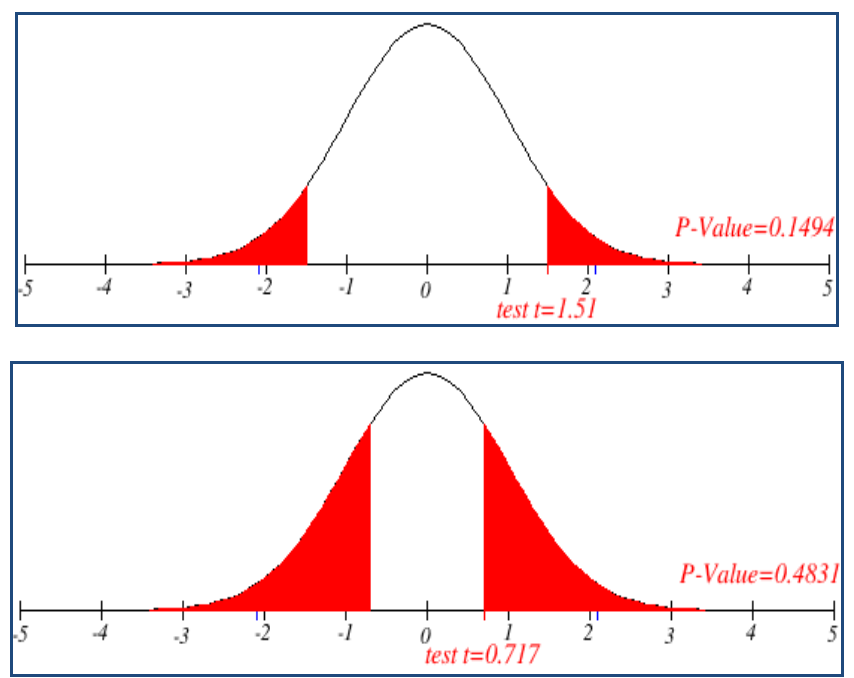

Figure 5. $t$-test and p-value for the Experimental (Pre-Test \& Post-Test) and Control (Pre-Test \& Post-Test) Groups of Health-Related Fitness (i.e., Muscular Endurance) of University Level Girls.

\subsection{Flexibility}

The results of components of health-related fitness in group (Experimental) and group (Control) are shown in Table 3 . The Mean and Standard Deviation $( \pm$ SD) values of flexibility of pre-test and post-test of experimental group were $26.56 \pm 5.23 \& 27.78 \pm 5.13$ respectively. However, the Mean and Standard Deviation $( \pm \mathrm{SD})$ values of flexibility of pre-test and post-test of control group were $23.11 \pm 3.92 \&$ $23.22 \pm 3.23$. The $t$-value in case of experimental group was 5.500* and for control group it was 0.316 .

Significant between-group differences were noted in flexibility in the experimental group before (Pre) and after (Post) subjected to 4-weeks surya nadi pranayama training programme since, the calculated value of $\left(t=5.500^{*}\right)$ is greater than tabulated value of $t_{.05}(17)=2.10$ for the selected degree of freedom and level of significance. However, no significant changes over that 4- weeks period were noted in the control group.
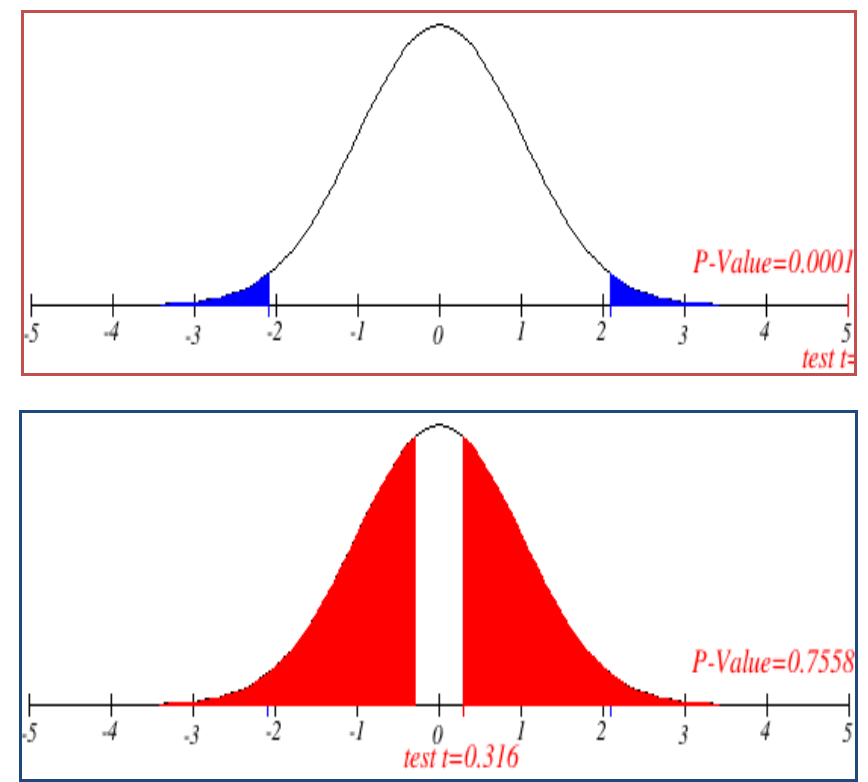

Figure 6. $t$-test and p-value for the Experimental (Pre-Test \& Post-Test) and Control (Pre-Test \& Post-Test) Groups of Health-Related Fitness (i.e., Flexibility) of University Level Girls.

\section{5. \% Body Fat}

The results of components of health-related fitness in group (Experimental) and group (Control) are shown in Table 3 . The Mean and Standard Deviation $( \pm \mathrm{SD})$ values of $\%$ body fat of pre-test and post-test of experimental group were $29.27 \pm 6.21 \& 29.26 \pm 6.20$ respectively. However, the Mean and Standard Deviation $( \pm \mathrm{SD})$ values of $\%$ body fat of pretest and post-test of control group were 25.10 $\pm 7.95 \&$ $25.10 \pm 7.94$. The t-value in case of experimental group was 1.492 and for control group it was 0.046 .

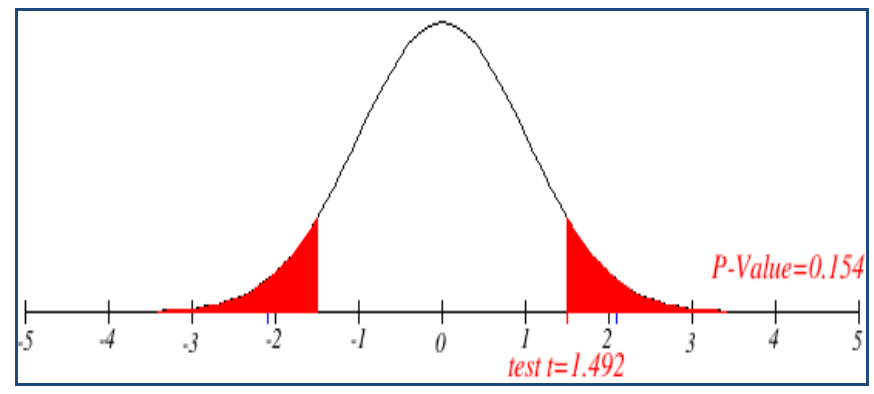




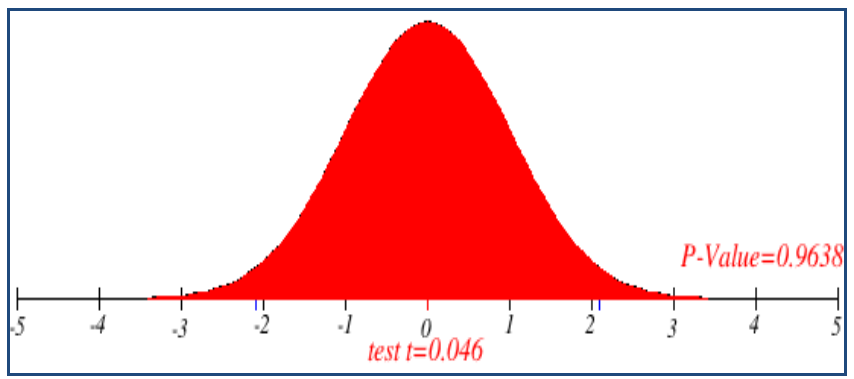

Figure 7. t-test and p-value for the Experimental (Pre-Test \& Post-Test) and Control (Pre-Test \& Post-Test) Groups of Health-Related Fitness (i.e., \% Body Fat) of University Level Girls.

Insignificant between-group differences were noted in \% body fat in the experimental group before (Pre) and after (Post) subjected to 4-weeks surya nadi pranayama training programme since, the calculated value of $(\mathrm{t}=1.492)$ is greater than tabulated value of $t .05(17)=2.10$ for the selected degree of freedom and level of significance. However, no significant changes over that 4 - weeks period were noted in the control group.
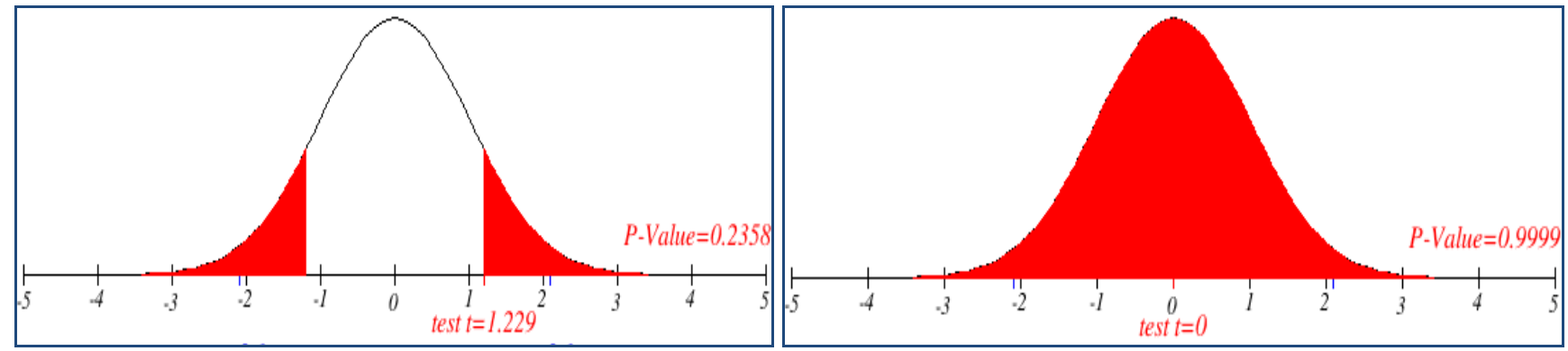

Figure 8. $t$-test and p-value for the Experimental (Pre-Test \& Post-Test) and Control (Pre-Test \& Post-Test) Groups of Health-Related Fitness (i.e., Fat Weight) of University Level Girls.
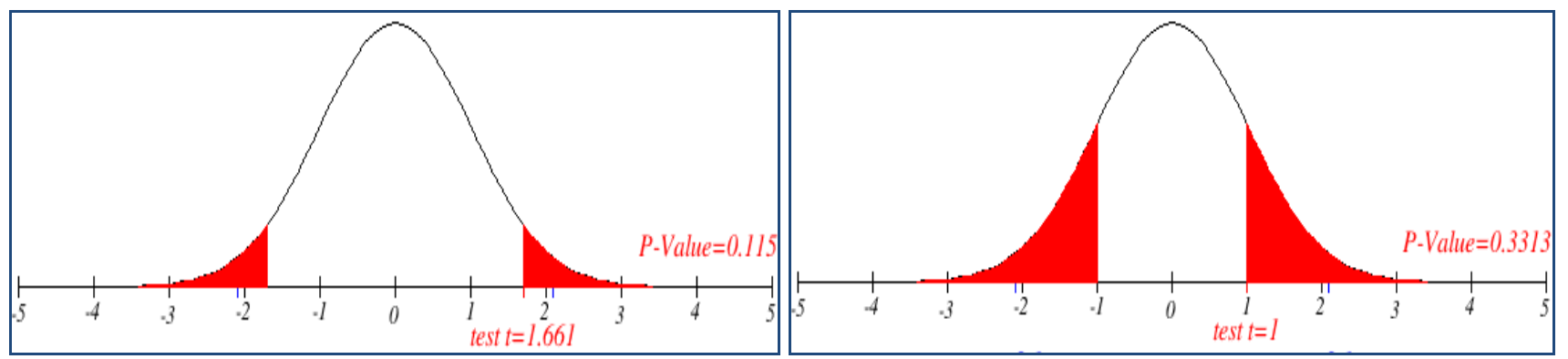

Figure 9. t-test and p-value for the Experimental (Pre-Test \& Post-Test) and Control (Pre-Test \& Post-Test) Groups of Health-Related Fitness (i.e., Lean Body Weight) of University Level Girls.

\subsection{Fat Weight}

The results of components of health-related fitness in group (Experimental) and group (Control) are shown in Table 3 . The Mean and Standard Deviation $( \pm \mathrm{SD})$ values of fat weight of pre-test and post-test of experimental group were $16.57 \pm 1.49 \& 16.56 \pm 1.48$ respectively. However, the Mean and Standard Deviation $( \pm \mathrm{SD})$ values of fat weight of pre-test and post-test of control group were $16.41 \pm 1.27$ \& $16.41 \pm 1.277$. The t-value in case of experimental group was 1.229 and for control group it was 0.000 .

Insignificant between-group differences were noted in fat weight in the experimental group before (Pre) and after (Post) subjected to 4-weeks surya nadi pranayama training programme since, the calculated value of $(\mathrm{t}=1.229)$ is greater than tabulated value of $t .05(17)=2.10$ for the selected degree of freedom and level of significance. However, no significant changes over that 4 - weeks period were noted in the control group. 


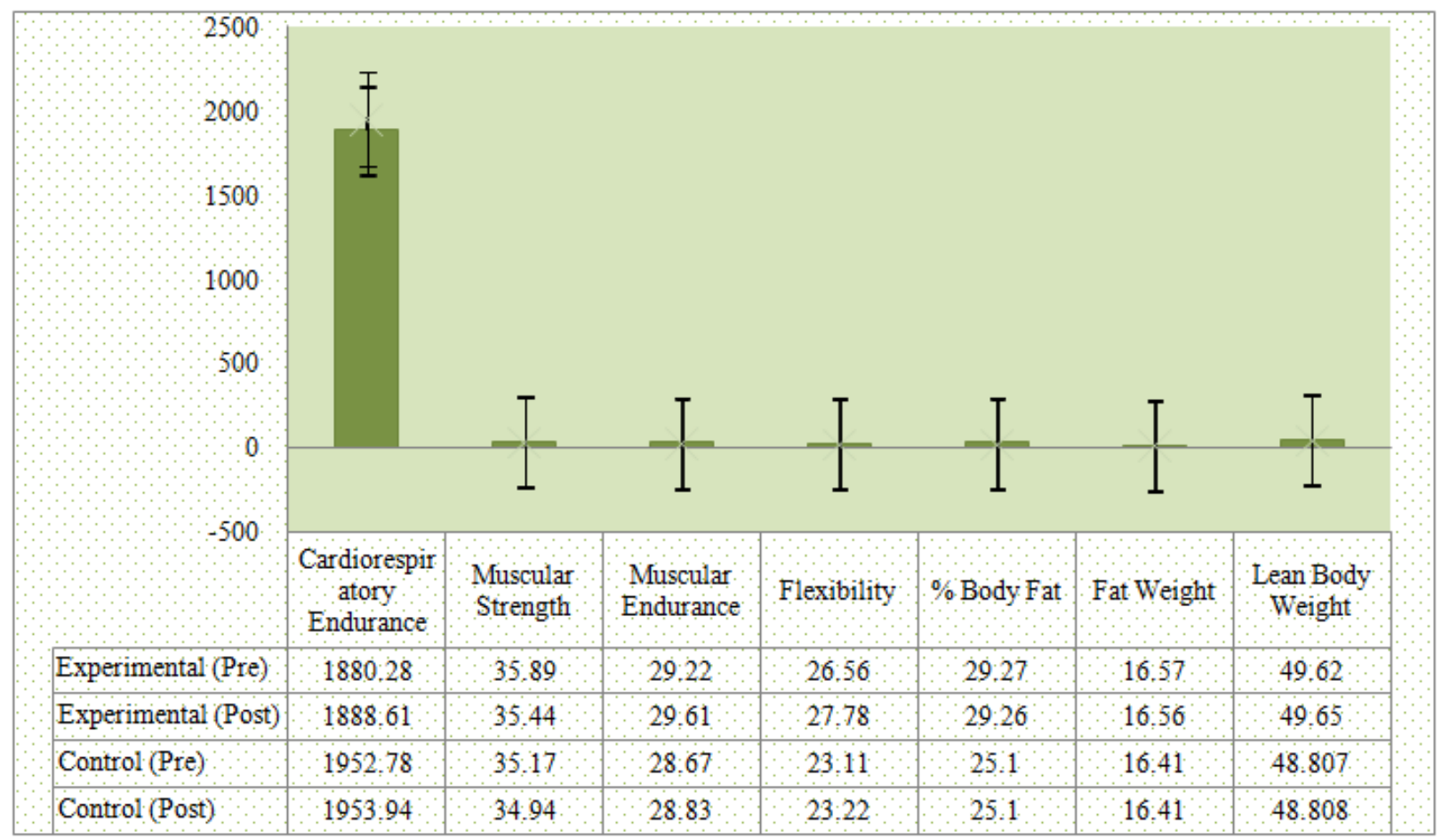

Figure 10. Mean values of Components of Health-Related Fitness (i.e., Cardiorespiratory Endurance, Muscular Strength, Muscular Endurance, Flexibility, \% Body Fat, Fat Weight and Lean Body Weight) in Experimental and Control group ( $n=18$ each) before (Pre) and after (Post) 4-weeks Surya Nadi Pranayama Training Programme (Experimental group only).

\subsection{Lean Body Weight}

The results of components of health-related fitness in group (Experimental) and group (Control) are shown in Table 3. The Mean and Standard Deviation $( \pm \mathrm{SD})$ values of lean body weight of pre-test and post-test of experimental group were $49.62 \pm 5.14$ \& $49.65 \pm 5.15$ respectively. However, the Mean and Standard Deviation $( \pm \mathrm{SD})$ values of lean body weight of pre-test and post-test of control group were $48.807 \pm 6.29$ \& $48.808 \pm 6.291$. The $t$-value in case of experimental group was 1.661 and for control group it was 1.000 .

Insignificant between-group differences were noted in lean body weight in the experimental group before (Pre) and after (Post) subjected to 4-weeks surya nadi pranayama training programme since, the calculated value of $(\mathrm{t}=1.661)$ is greater than tabulated value of $t .05(17)=2.10$ for the selected degree of freedom and level of significance. However, no significant changes over that 4 - weeks period were noted in the control group.

\section{Conclusion}

Based on the analysis of the results obtained, we conclude that the significant differences were found in Components of Health-Related Fitness (i.e., cardiorespiratory endurance, flexibility) of university level girls. Insignificant betweengroup differences were noted in muscular strength, muscular endurance, \% body fat, fat weight and lean body weight of university level girls.

\section{References}

[1] Bijilani, R.L. (2004). The Yogic Practices: Asanas, Pranayamas and Kriyas. Understanding medical physiology, $3^{\text {rd }}$ edition, Jaypee Brothers Medical Publishers, New Delhi, India, 883-889.

[2] Gharote, M.L. (2003). Pranayama - the science of breath theory and guidelines for practice, 1st edition Pune, 9.

[3] Madanmohan. (2005). Effect of slow and fast pranayamas on reaction time and cardiorespiratory variables. Indian J Physiol Pharmacol. 49(3), 313-18.

[4] Shivraj, P., Manaspure, A.F., Damodara, G. (2001). Effect of selected breathing techniques on respiratory rate and breath holding time in healthy adults. IJABPT, 2(3), 25-29.

[5] Subalakshmi, N.K., Saxena, S.K., Urmimala, Urban, \& D'Souza. (2005). Immediate effect of Nadi-Shodhana pranayama on some selected parameters of cardiovascular, pulmonary, and higher functions of brain. TJPS. 18(2), 10-16.

[6] Pal, G.K., Velkumary, S., \& Madanmohan. (2004). Effect of short-term practice of breathing exercises on autonomic functions in normal human volunters. Indian J Med Res. 120, 15- 121 .

[7] Ropa, B.A., Anita, H., Shailaja, P., Shashikala, G.V., \& Surekharani, C. (2001). Effect of Short-Term Pranayama and Meditation on Cardiovascular Functions in Healthy Individuals. Heart Views. 12(2), 58-62. 